\title{
Complete genome sequence of Planococcus sp. PAMC21323 isolated from Antarctica and its metabolic potential to detoxify pollutants
}

\author{
Jong-Hyun Jung ${ }^{1,2}$, Min-Ho Joe ${ }^{1}$, Dong-Ho Kim ${ }^{1}$, Hyun Park ${ }^{3}$, Jong-il Choi ${ }^{4^{*}}$ and Sangyong Lim ${ }^{1,2^{*}}$ (D)
}

\begin{abstract}
The Planococcus sp. PAMC21323 is a yellow pigment-producing bacterium isolated from King George Island in Antarctica; it has a broad growth temperature range of 5-40 ${ }^{\circ} \mathrm{C}$. Herein, we describe the complete genome sequence information of the genus Planococcus with its annotated sequence, genetic features for bioremediation, and oxidative stress capacity. The Planococcus sp. PAMC21323 possesses chromosomal DNA (3,196,500-bp) with plasmid DNA (3364-bp). The complete 3,199,864-bp of the genome consists of 3171 genes including 60 transfer RNAs and 24 ribosomal RNAs. Strain PAMC21323 encodes various genes associated with detoxification of heavy metal ions and aromatic hydrocarbons. Moreover, it is equipped with diverse stress response systems, which can be used to sense the internal and oxidative stresses caused by detoxification. This is the first report highlighting the genetic potential of Planococcus sp. PAMC21323 in bioremediation, suggesting application of this psychrotrophic strain in bioremediation in harsh environments.
\end{abstract}

Keywords: Planococcus, Antarctica, Psychrophiles, Bioremediation

\section{Introduction}

Increasing environmental pollution caused by industrial and other anthropogenic activities has become a major threat to the survival of living organisms. Microorganismmediated degradation of pollutants such as hydrocarbons and heavy metal ions into non- or less-hazardous substances is an inexpensive and efficient method for clean-up and restoring contaminated areas, hence the applications of various microorganisms for bioremediation, such as Pseudomonas, Burkholderia and Rhodococcus, have been a focus of numerous studies [1]. During the detoxification of pollutants, cells are exposed to abundant reactive oxygen species (ROS) [2]. Therefore, strong stress resistance of the host organism can help improve bioremediation capacity. The cold-adapted bacteria are

\footnotetext{
* Correspondence: choiji01@jnu.ac.kr; saylim@kaeri.re.kr

${ }^{4}$ Department of Biotechnology and Bioengineering, Chonnam National University, Gwangju 61186, Republic of Korea

${ }^{1}$ Research Division for Biotechnology, Korea Atomic Energy Research

Institute, Jeongeup 56212, Republic of Korea

Full list of author information is available at the end of the article
}

generally equipped with diverse stress response systems owing to the fact that the cold environment is a major cause of multiple stresses such as osmotic, alkali, and oxidative stress [3]. Consequently, particular interest has arisen in regard to the bioremediation ability of psychrotrophs and psychrophiles $[4,5]$. Polar regions, including Antarctica, are putative reservoirs of genetic resources for bioremediation. It has been reported that diverse bacteria isolated in Antarctica are resistant to multiple metal ions [6] and can degrade hydrocarbons [7]. Moreover, coldadapted bacteria can be used to remove contaminants in cold terrestrial sites where mesophilic microorganisms do not survive [4].

Planococcus spp. are gram-positive (+) bacteria in the family of Planococcaceae (Bacillales, Firmicutes). This genus had previously been categorized as Micrococci, but the motile cocci in the genus Micrococcus was reclassified as the genus Planococcus by Migula in 1894, and its chemosystematic properties were demonstrated by Kocur et al. [8]. To date, 18 type strains have been characterized. Most Planococcus spp. are predominantly 
found in cold marine environments. They account for $5.8 \%$ of the total bacterial community in the Arctic permafrost [9] and can survive in high salinity regions such as Arctic spring channels [10].

Within the genus, Planococcus halocryophilus is known to be tolerant to high levels of salinity (19\% $\mathrm{NaCl})$ and grows under subzero temperature $\left(10{ }^{\circ} \mathrm{C}\right)$ [9]. The genome analysis of $P$. halocryophilus Or1 shows that it harbors cold- and osmotic-specific mechanisms and multiple copies of isozymes to maintain the cellular system in harsh conditions [11]. Interestingly, some Planococcus spp. exhibit heavy-metal resistance and are capable of degrading linear alkanes or aromatic hydrocarbons [12, 13]. The Planococcus sp. S5 grows on salicylate or benzoate and also produces a catechol 2, 3-dioxygenase that shows high reactivity toward 4-chlorocatechol [12]. The haloalkaliphilic bacterium Planococcus sp. ZD22 can not only degrade benzene, toluene, xylene, and halogenated benzene, but also use them as sole carbon source [13]. These examples demonstrate that Planococcus spp. are credible candidates for utilization in bioremediation resource processes in harsh conditions. However, there have been no reports of the genome features associated with bioremediation pathways, even though 10 genomes of Planococcus spp. have been sequenced to date. Many studies have focused on adaption mechanisms of the Planococcus spp. under high salt environments or subzero conditions [11].

In this study, we present the complete genome sequence of the psychrotroph Planococcus sp. PAMC21323, isolated from King George Island of the South Shetland Islands in Antarctica (62 $\left.07^{\prime} 48^{\prime \prime} \mathrm{S}, 58^{\circ} 28^{\prime} 12^{\prime \prime} \mathrm{W}\right)$, and its genetic properties associated with pollutant degradation and stress resistance.

\section{Organism information}

\section{Classification and features}

Planococcus sp. PAMC21323 is a gram (+), motile, psychrotrophic bacteria, which can grow over a broad temperature range $\left(5-40{ }^{\circ} \mathrm{C}\right)$. Microscopically, it is a cocci-shaped bacterium measuring 0.5 to $0.7 \mu \mathrm{m}$ in diameter (Fig. 1a). Colonies are round and yellow in color. The general features of Planococcus sp. PAMC21323 are shown in Table 1. Based on multiple alignments of $16 \mathrm{~S}$ ribosomal RNA (rRNA) sequences of Planococcus type strains and Planococcus sp. PAMC21323, a phylogenetic tree was constructed using neighbor-joining methods of the MEGA5 program [14] with 1000 bootstrap replicates. Planococcus sp. PAMC21323 appeared to represent a phylogenetically coherent group with P. halocryophilus and Planococcus donghaensis (Fig. 1b). BLASTN analysis revealed that the 16S rRNA sequence of these strains shared 99\% similarity.

\section{Genome sequencing information Genome project history}

Planococcus spp. are psychrotrophic bacteria that exhibit high resistance toward salt and cold conditions $[10,15]$. Some Planococcus species were found to show bioremediation activities, but their genetic features related with bioremediation were not investigated [13]. In this study, we isolated the psychrotrophic Planococcus sp. PAMC21323 strain from King George Island in the Antarctic and sequenced the genome to investigate its bioremediation potential and stress resistance capacity. The genome project has been deposited in the Genome Online Database [16], and more detailed information is provided in Table 2. The complete genome sequence of the
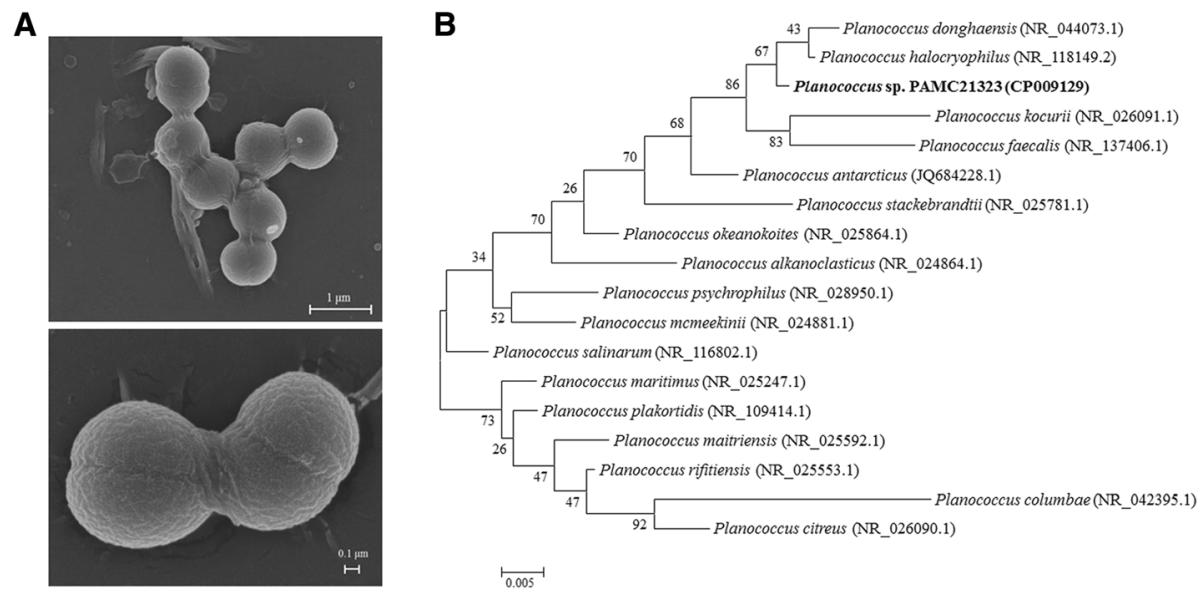

Fig. 1 Scanning electron micrograph of Planococcus sp. PAMC21323 (a) and Phylogenetic analysis of Planococcus sp. PAMC21323 relative to nearest-neighboring Planococcus type strains $(\mathbf{b})$ : The $16 \mathrm{~s}$ sequences were obtained from the NCBI database and aligned using ClustalOmega. Phylogenetic tree constructed with the Maximum-Likelihood algorithm of MEGA 6.0. Bootstrap values were determined from 1000 replicates 
Table 1 Classification and general features of Planococcus sp. PAMC21323 according to the MIGS recommendation [42]

\begin{tabular}{|c|c|c|c|}
\hline MIGS ID & Property & Term & Evidence code $^{a}$ \\
\hline & Classification & Domain Bacteria & TAS [43] \\
\hline & & Phylum Firmicutes & TAS $[43,44]$ \\
\hline & & Class Bacilli & $\operatorname{TAS}[43,45]$ \\
\hline & & Order Bacillales & $\operatorname{TAS}[43,46]$ \\
\hline & & Family Planococcaceae & TAS $[8,46]$ \\
\hline & & Genus Planococcus & TAS $[8,46]$ \\
\hline & & Species PAMC21323 & \\
\hline & Gram stain & Gram positive & TAS [8] \\
\hline & Cell shape & Coccus & IDA \\
\hline & Motility & Motile & IDA \\
\hline & Sporulation & No spore & IDA \\
\hline & Temperature range & $5-40{ }^{\circ} \mathrm{C}$ & IDA \\
\hline & Optimum temperature & $25^{\circ} \mathrm{C}$ & IDA \\
\hline & pH range; optimum & $4-8 ; 7.5$ & IDA \\
\hline & Carbon source & Glucose, maltose, sucrose, xylose & IDA \\
\hline MIGS-6 & Habitat & Soil (sea shore) & IDA \\
\hline MIGS-6.3 & Salinity & Up to $10 \%$ & IDA \\
\hline MIGS-22 & Oxygen requirement & Aerobic & IDA \\
\hline MIGS-15 & Biotic relationship & Not reported & \\
\hline MIGS-14 & Pathogenicity & Non-pathogenic & NAS \\
\hline MIGS-4 & Geographic location & King George Island, Antarctica & IDA \\
\hline MIGS-5 & Sample collection & July 30, 2004 & IDA \\
\hline MIGS-4.1 & Latitude & -62.13000 & IDA \\
\hline MIGS-4.2 & Longtitude & -58.4700 & IDA \\
\hline MIGS-4.4 & Altitude & 9 & IDA \\
\hline
\end{tabular}

aEvidence codes - IDA Inferred from Direct Assay, TAS Traceable Author statement (i.e., a direct report exists in the literature), NAS Non-traceable Author statement (i.e., not directly observed for the living, isolated sample, but based on a generally accepted property for the species, or anecdotal evidence). These evidence codes are from the Gene Ontology project [47]

Table 2 Genome sequencing project information

\begin{tabular}{lll}
\hline MIGS ID & Property & Term \\
\hline MIGS-31 & Finishing quality & Finished \\
MIGS-28 & Libraries used & 4543 kb paired end library, Illumina 150 bp paired end library \\
MIGS-29 & Sequencing platforms & $454-G S-F L X$ Titanium \\
MIGS-31.2 & Fold coverage & Illumina Hiseq 2000 \\
MIGS-30 & Assemblers & 1874-fold coverage \\
MIGS-32 & Gene calling method & gsAssembler 2.6 \\
& Locus_Tag & Glimmer 3.02 \\
& Genbank ID & Plano \\
& Genbank Data of Release & CP009129, CP009130 \\
& GOLD ID & $11 / 19 / 2014$ \\
& BIOPROJECT & Gp0101987 \\
MIGS-13 & Project relevance & PRJNA256273 \\
\hline
\end{tabular}


Planococcus sp. PAMC21323 is available in the GenBank database.

\section{Growth conditions and genomic DNA preparation}

The Planococcus sp. PAMC21323 was cultivated aerobically at $25{ }^{\circ} \mathrm{C}$ in a marine broth medium. The genomic DNA was isolated using a Masterpure ${ }^{\mathrm{Tm}}$ Gram Positive DNA Purification Kit (Epicenter, Madison WI, USA), according to the standard protocol of the manufacturer.

\section{Genome sequencing and assembly}

The genome of Planococcus sp. PAMC21323 was sequenced based on a hybrid strategy using a Roche 454 GS FLX Titanium and an Illumina HiSeq 2000. An 8-kb paired-end library of 454-pyrosequencing, and a 150-bp paired-end library of Illumina, generated 238,440 and $58,949,907$ reads, respectively. The CLCbio Genomics Workbench 6.5 software and the Roche gsAssembler 2.6 were used to assemble 1874-fold coverage data of the genome sequence, generating 2 scaffolds with 18 contiguous sequences (contigs). The gaps between the contigs were closed by polymerase chain reaction (PCR) and Sanger sequencing, yielding a genome size of 3,199,864-bp, which consists of one circular chromosome of 3,196,500-bp and one circular plasmid of 3364-bp. The complete genome sequence of Planococcus sp. PAMC21323 has been deposited in the GenBank database under accession number CP009129 (Chromosome) and CP009130 (Plasmid).

\section{Genome annotation}

The open reading frames (ORFs) in the complete genome were predicted using a Glimmer 3.02 and a Rapid Annotation using Subsystem Technology (RAST) server [17]. BLASTP analysis based on a non-redundant database and Clusters of Orthologous Groups of proteins (COGs), InterProScan, Pfam, and TIGRFAM databases, was performed to identify the functionality of ORFs $[18$, 19]. tRNAscan-SE [20] and HMMER [21] were used to identify the transfer RNA (tRNA) and rRNA, respectively. To examine the mobile elements and genomic island (GI) regions, PHAST [22] and IslandViewer (based on the SIGI_HMM, and IslandPath-DIMOB algorithm) [23] were implemented, respectively. Other miscellaneous features were predicted using TMHMM [24] and SignalP [25].

\section{Genome properties}

The complete genome of Planococcus sp. PAMC21323 consists of chromosomal and extrachromosomal elements with a total length of 3,199,864-bp and GC content of 39.3\%. The circular chromosome of 3,196,500-bp (39.3\% GC content) was predicted to have 3169 genes, including 60 tRNAs and 24 rRNAs (Table 3). The
Table 3 Genome statistics of Planococcus sp. PAMC21323

\begin{tabular}{lll}
\hline Attribute & Value & \% of total \\
\hline Genome size (bp) & $3,199,864$ & 100.00 \\
DNA coding region (bp) & $2,761,854$ & 86.31 \\
DNA G + C (bp) & $1,258,557$ & 39.33 \\
DNA scaffolds & 2 & - \\
Total genes & 3171 & 100.00 \\
Protein coding genes & 3087 & 97.35 \\
RNA genes & 84 & 2.65 \\
Pseudo genes & 27 & 0.85 \\
Genes in internal clusters & 270 & 8.51 \\
Gene with function prediction & 2632 & 83.00 \\
Genes assigned to COGs & 2294 & 72.34 \\
Genes assigned Pfam domains & 2676 & 84.39 \\
Genes with signal peptides & 128 & 4.04 \\
Genes with transmembrane helices & 840 & 26.49 \\
CRISPR repeats & 1 & -
\end{tabular}

The total is based on either the size of the genome in base pairs or the total number of protein coding genes in the annotated genome

extrachromosomal element had a length of 3364-bp (33.3\% GC content) that encodes two predicted protein-coding genes. Of the total 3171 genes predicted, 3087 were protein-coding genes. The majority (2632 ORF, 85.2\%) of all protein-coding genes were assigned with a putative function, whereas the remaining 455 genes were hypothetical proteins. In addition, 2676 ORFs (86.4\%) contained at least one or several Pfam domains. The genome summary and COGs categories are listed in Tables 3 and 4. Among the 18 strains identified as a type of the genus Planococcus, 10 genome sequences have been registered in the NCBI genome database. The relationship with the other genome sequenced species was calculated based on the average nucleotide identity (ANI) using JSpecies [26]. Planococcus sp. PAMC21323 had the highest similarity with $P$. halocryophilus (86.8\%) and P. donghaensis (86.1\%) (Fig. 2). An ANI identity value under $96 \%$ shows that PAMC21323 is distinguishable from the other strains.

\section{Insights from the genome sequence}

\section{Diverse mobile genetic elements}

The mobile elements, such as integrases and transposases, are important genetic components involved in acquisition of new genes, which can expand a genome diversity and adaptation to a new environment [27]. We found that the genome of Planococcus sp. PAMC21323 contained 15 putative mobile elements (12 transposases, two integrases, and one Tn552 transposon) known to facilitate horizontal gene transfer (Fig. 3). The number of transposase units found in Planococcus sp. PAMC21323 was the same as that in $P$. halocryophilus (12 
Table 4 Number of genes associated with general COG functional categories

\begin{tabular}{|c|c|c|c|}
\hline Code & Value & $\%$ age & Description \\
\hline J & 217 & 8.26 & Translation \\
\hline A & 0 & 0.00 & RNA processing and modification \\
\hline K & 167 & 6.36 & Transcription \\
\hline $\mathrm{L}$ & 102 & 3.88 & Replication, recombination and repair \\
\hline B & 1 & 0.04 & Chromatin structure and dynamics \\
\hline D & 42 & 1.60 & Cell cycle control, mitosis and meiosis \\
\hline Y & 0 & 0.00 & Nuclear structure \\
\hline V & 59 & 2.25 & Defense mechanisms \\
\hline $\mathrm{T}$ & 128 & 4.87 & Signal transduction mechanisms \\
\hline M & 140 & 5.33 & Cell wall/membrane biogenesis \\
\hline N & 45 & 1.71 & Cell motility \\
\hline Z & 0 & 0.00 & Cytoskeleton \\
\hline W & 8 & 0.30 & Extracellular structures \\
\hline U & 29 & 1.10 & Intracellular trafficking and secretion \\
\hline O & 115 & 4.38 & Posttranslational modification, protein turnover, chaperones \\
\hline C & 131 & 4.99 & Energy production and conversion \\
\hline G & 160 & 6.09 & Carbohydrate transport and metabolism \\
\hline E & 257 & 9.78 & Amino acid transport and metabolism \\
\hline $\mathrm{F}$ & 96 & 3.65 & Nucleotide transport and metabolism \\
\hline H & 141 & 5.37 & Coenzyme transport and metabolism \\
\hline । & 148 & 5.63 & Lipid transport and metabolism \\
\hline P & 138 & 5.25 & Inorganic ion transport and metabolism \\
\hline Q & 69 & 2.63 & Secondary metabolites biosynthesis, transport and catabolism \\
\hline $\mathrm{R}$ & 255 & 9.71 & General function prediction only \\
\hline S & 167 & 6.36 & Function unknown \\
\hline$x$ & 12 & 0.46 & Mobilome: prophage, transposons \\
\hline- & 877 & 27.66 & Not in COGs \\
\hline
\end{tabular}
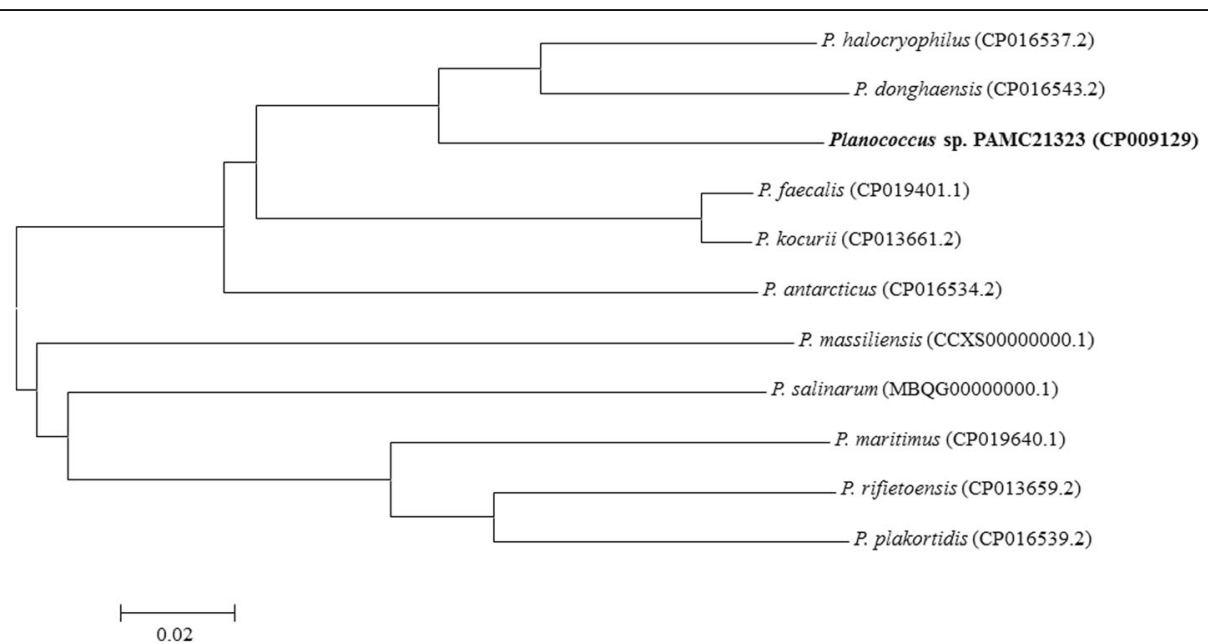

Fig. 2 The relationship of the genome sequences of Planococcus type strains and PAMC21323 based on the average nucleotide identity values. The bar reflects normalized pairwise genomic distance between genomes 

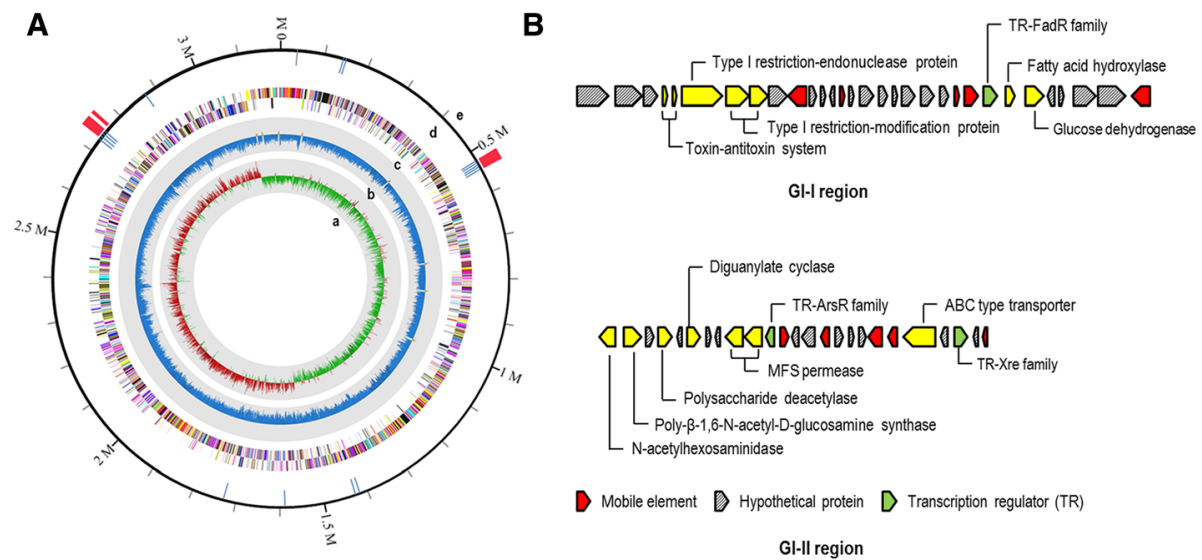

Fig. 3 A circular map of the genome of Planococcus sp. PAMC21323 (a) and gene cluster of genomic islands (b). Starting from the inner circle moving outwards, the following tracks are shown: Circle a, positive (red) and negative (green) GC skew; circle b, GC content; circle c, predicted protein coding genes on forward and reverse strand colored to COG categories; circle d, the location of mobile elements (blue); circle e, genomic islands (red)

transposases) but higher than that in $P$. donghaensis (4 transposases) [11]. Interestingly, of the total mobile elements, nine genes were positioned in GI regions, which were identified by IslandViewer 3.0. In the genome of Planococcus sp. PAMC21323, three putative GI regions with $24.2 \mathrm{~kb}, 21.4 \mathrm{~kb}$, and $7.5 \mathrm{~kb}$ length, respectively, were observed (Fig. 3). The GI-I region contained five transposase-encoding genes (Plano_0544, 0548, 0556, 0557, and 0566), and four transposase-encoding genes (Plano_2675, 2678, 2683, and 2688) were present in the GI-II region (Fig. 3). Three GI regions account for $1.6 \%$ of total chromosomal DNA and include 52 protein coding sequences (Additional file 1: Table S1). Notably, several defense systems were also observed in the GI-I region, one of which was a restriction-modification system (R/M system), a defense system to recognize and remove foreign DNA. Upstream of the R/M system, we found a toxin-antitoxin component (YefM/YoeB family, Plano_0538/0549), which is a stress response module inducing a persistence state that allows cells to cope with different type of stress such as nutrient starvation and temperature stress [28]. The GI-II regions mainly consisted of cell wall modification enzymes, which are known to contribute to cell wall stability and are required to endure osmotic stress [29].

\section{Genetic features for bioremediation}

In the genome of Planococcus sp. PAMC21323, various detoxification enzymes for aromatic hydrocarbons, nitroalkanes, and heavy metal ions were identified (Table 5). Planococcus sp. PAMC21323 has three extradiol dioxygenases (Plano_0315, 2898, and 2901) that catalyze the cleavage of the aromatic ring structure [30]. Among the enzymes, Plano_2898 and Plano_2901 contain 2, 6dichloro- $p$-hydroquinone 1, 2-dioxygenase conserved domain (PcpA, pentachlorophenol dioxygenase A), which is probably capable of cleaving aromatic compounds such as $\gamma$-hexachlorocyclohexane and 3-nitrophenol. The coexistence of PcpA (2898 and 2901) and PcpB (Plano_2834) shows the possibility that this strain might have the ability

Table 5 Identified bioremediation associated genes in PAMC21323

\begin{tabular}{|c|c|c|c|c|}
\hline Function & Enzyme & Locus_tag & & \\
\hline \multirow[t]{2}{*}{ Aromatic hydrocarbon degradation } & Extradiol dioxygenase & Plano_2898 & Plano_2901 & Plano_0315 \\
\hline & Pentachlolophenol-4-monooxygenase & Plano_2834 & & \\
\hline \multirow[t]{3}{*}{ Nitroalkane degradation } & Nitropropane dioxygenase & Plano_2019 & Plano_2569 & \\
\hline & Nitroreductase & Plano_0226 & Plano_0336 & Plano_2301 \\
\hline & Azoreductase & Plano_0380 & & \\
\hline \multirow[t]{2}{*}{ Metal ion detoxification } & Arsenate reductase & Plano_0840 & Plano_1482 & Plano_0928 \\
\hline & Mecuric ion reductase & Plano_1475 & & \\
\hline \multirow[t]{2}{*}{ Tellurite resistance } & TelA & Plano_1607 & & \\
\hline & TehB & Plano_1454 & & \\
\hline
\end{tabular}


to degrade pentachlorophenol, which is an extremely toxic compound in humans, leading to hyperthermia and convulsions [31].

Nitroalkane is a type of organic compound containing a nitro group, which is widely used in industry because it is an intermediate compound in chemical synthesis. It has been known to induce oxidative DNA damage and shown to be carcinogenic [32]. Nitropropane dioxygenase is a member of the nitroalkane oxidizing enzyme family. This enzyme catalyzes the oxidative denitrification of nitroalkane [33]. Planococcus sp. PAMC21323 has two nitropropane dioxygenases (Plano_2019 and 2569). It also has three nitroreductases (Plano_226, 336, and 2301) and one azoreductase (AzoR, Plano_0380), which are generally observed in bacteria isolated from soil contaminated with industrial pollutants like trinitrotoluene (dynamite) [34].

For the detoxification of heavy metal ions, Planococcus sp. PAMC21323 has three arsenate reductases (Table 5). Plano_1482 and 0840 encoded a low molecular-weight phosphatase (LMWP) family arsenate reductase, whereas Plano_0928 encoded a different type of arsenate reductase from the ArsC family. The LMWP family requires thioredoxin for arsenate reduction, while the ArsC family uses glutaredoxin. It is worth noting that the two LMWP family arsenate reductases are adjacent to the $\mathrm{ABC}$ transporter; especially Plano_1482, which was placed together with mercuric ion reductase (Plano_1475) under control of the ArsR family transcription regulator (Plano_1481). In addition, Planococcus sp. PAMC21323 also harbors two genes related to tellurite resistance; TelA (Plano_1607) has been established as a determination of tellurite resistance, and the methylase activity of TehB (Plano_1454) has a direct role in tellurite detoxification [35].

\section{Stress response system of Planococcus}

Bacteria subjected to bioremediation go through oxidative stress and exhibit high stress resistance because toxic pollutants are metabolized via oxygenase-type enzymes on the catabolic pathway [2]. Accumulation of heavy metal ions strongly induces generation of ROS [36, 37]. In Pseudomonas, which has been widely used for bioremediation, transcription of superoxide dismutase $(s o d)$ genes is induced in the presence of toxic compounds such as phenol, cadmium, and toluene, to remove ROS generated by the compounds [36].

Genome analysis of Planococcus sp. PAMC21323 revealed that it has diverse oxidative stress responserelated genes (Table 6). To remove superoxide radicals generated from reactions of the various oxygenases, it has two different types of SODs, differentiated by the metal ion cofactor: Mn/Fe SOD (Plano_1316) and $\mathrm{Cu} /$ Zn SOD (Plano_2589). Additionally, three catalases, eight peroxiredoxin (Prx) family enzymes, and glutathione peroxidase (GPx) were observed, which are involved in the ROS defense system (Table 6). Planococcus sp. PAMC21323 is equipped with one glutaredoxin, eight thioredoxins (TrxA), and three thioredoxin reductases (TrxR) associated with redox balance (Table 6).

To reduce thiol-modification in proteins caused by ROS, most microorganisms use low-molecule thiol cofactors. Low-GC gram (+) Firmicutes (Bacillus and Staphylococcus) use the bacillithiol (BSH), and high-GG gram (+) Actinomycetes such as Mycobacterium produce mycothiol

Table 6 Identified oxidative stress response related genes in PAMC21323

\begin{tabular}{lll}
\hline Gene & Product & Locus_tag \\
\hline Kat & Iron catalase & Plano_0228; Plano_0269 \\
& bifunctional catalase peroxidase & Plano_2972 \\
Sod & Mn/Fe superoxide dismutase & Plano_1316 \\
& Cu/Zn superoxide dismutase & Plano_2589 \\
Prx & Thiol-peroxidase & Plano_1084 \\
& PrxQ (BCP) & Plano_0810 \\
& Prx-like protein & Plano_1452; Plano_1670; Plano_1816; Plano_2134 \\
& Alkyl hydroperoxide reductase C & Plano_2964 \\
& Alkyl hydroperoxide reductase F & Plano_2965 \\
TrxA & Thioredoxin & Plano_0462; Plano_0753; Plano_0826; Plano_0924; Plano_0931; Plano_1054; Plano_1156; \\
& & Plano_1389; Plano_1669 \\
TrxB & Thioredoxin reductase & Plano_0301; Plano_0900; Plano_1802 \\
Gpx & Glutathione peroxidase & Plano_2887 \\
GR & Glutathione reductase & Plano_2022 \\
Grx & Glutaredoxin & Plano_1634 \\
\hline
\end{tabular}


(MSH) [38]. Interestingly, we found that Planococcus sp. PAMC21323 has a bifunctional glutathione synthase (Plano_1675), glutathione peroxidase (Plano_2887), and NADPH-dependent glutathione reductase (Plano_2022), involved in glutathione (GSH) maintenance. This indicates that Planococcus sp. PAMC21323 has a GSH redox buffer system, and not a bacillithiol-based system, despite its genome similarity with Bacillus. Since GSH exhibits a higher capacity to buffer oxidative stress than BSH [39], it may help Planococcus sp. PAMC21323 to endure oxidative stress.

Like other psychrophilic bacteria, Planococcus sp. PAMC21323 produces a yellow-like pigment as a secondary metabolite. The genome analysis revealed that the pigment is synthesized by a series of genes (Plano_2714 2718). In cold environments, pigments can act as modulators of membrane fluidity and maintain proton permeability [40]. Moreover, its antioxidant activity can not only protect the cell against cold and oxidative stress, but also reduce the cytotoxicity of heavy metal ions such as copper [41].

\section{Conclusion}

The genus Planococcus grows well under low temperature and high salinity conditions and some Planococcus strains are known to have the ability to detoxify pollutants. The psychrotrophic Planococcus sp. PAMC21323 was isolated from King George Island in Antarctica. From our analysis of the genome, we identified that Planococcus sp. PAMC21323 encodes various genes associated with detoxification of pollutants and possesses a variety of oxidative stress systems to reduce toxicity during bioremediation. Analyzing the genome sequence of Planococcus sp. PAMC21323 has shown the potential application of this psychrotrophic strain for bioremediation in harsh environments.

\section{Additional files}

Additional file 1: Table S1. List of genes in genomic island regions. (XLSX $14 \mathrm{~kb})$

\section{Abbreviations}

ANI: Average nucleotide identity; LMWP: Low molecular-weight phosphatase; ROS: Reactive oxygen species; SOD: Superoxide dismutase

\section{Acknowledgements \\ The authors thank Dr. Yong-Joon Cho in Chunlab. Inc. for genome sequence assembly. This work was supported by a Nuclear R\&D program of Ministry of Science and Information and Communications Technologies (Republic of Korea), by the National Research Foundation of Korea (NRF) grant funded by the Korea government (MSIP) (No.NRF-2018R1D1A1B07049359) and by Golden Seed Project (213008-05-2-SB910), Ministry of Oceans and Fisheries.}

\section{Funding}

This work was funded by a Nuclear R\&D program of Ministry of Science and Information and Communications Technologies (Republic of Korea), by the National Research Foundation of Korea (NRF) grant (No.NRF-
2018R1D1A1B07049359) and by Golden Seed Project (213008-05-2-SB910) of Ministry of Oceans and Fisheries.

\section{Authors' contributions}

SL and JC conceived the project. HP and JC isolated the strain PAMC21323 and generated all of the physiological data. MJ and DK extracted the genomic DNA and performed the genome sequencing. JJ annotated and analyzed the genome of the strain. JJ and SL wrote the manuscript. All authors read and approved final manuscript.

\section{Competing interests}

The authors declare that they have no competing interests.

\section{Publisher's Note}

Springer Nature remains neutral with regard to jurisdictional claims in published maps and institutional affiliations.

\section{Author details}

${ }^{1}$ Research Division for Biotechnology, Korea Atomic Energy Research Institute, Jeongeup 56212, Republic of Korea. ${ }^{2}$ Department of Radiation Biotechnology and Applied Radioisotope Science, University of Science and Technology, Daejeon 34113, Republic of Korea. ${ }^{3}$ Korea Polar Research Institute, Incheon 21990, Republic of Korea. ${ }^{4}$ Department of Biotechnology and Bioengineering, Chonnam National University, Gwangju 61186, Republic of Korea.

Received: 11 October 2017 Accepted: 25 October 2018

Published online: 09 November 2018

References

1. Vogt $\mathrm{C}$, Richnow HH. Bioremediation via in situ microbial degradation of organic pollutants. Adv Biochem Eng Biotechnol. 2014;142:123-46.

2. Pandey G, Jain RK. Bacterial chemotaxis toward environmental pollutants: role in bioremediation. Appl Environ Microbiol. 2002;68:5789-95.

3. Sengupta D, Sangu K, Shivaji S, Chattopadhyay MK. Tolerance of an Antarctic bacterium to multiple environmental stressors. Curr Microbiol. 2015;71:483-9.

4. Gratia E, Weekers F, Margesin R, D'Amico S, Thonart P, Feller G. Selection of a cold-adapted bacterium for bioremediation of wastewater at low temperatures. Extremophiles. 2009;13:763-8.

5. Michaud L, Lo Giudice A, Saitta M, De Domenico M, Bruni V. The biodegradation efficiency on diesel oil by two psychrotrophic Antarctic marine bacteria during a two-month-long experiment. Mar Pollut Bull. 2004; 49:405-9.

6. De Souza MJ, Loka Bharathi PA, Nair S, Chandramohan D. "trade-off" in Antarctic bacteria: limnetic psychrotrophs concede multiple enzyme expressions for multiple metal resistance. Biometals. 2007;20:821-8.

7. Jesus HE, Peixoto RS, Rosado AS. Bioremediation in Antarctic soils. J Pet Environ Biotechnol. 2015;6:248.

8. Kocur M, Zdena P, Hodgkiss W, Martinec T. The taxonomic status of the genus Planococcus Migula 1894. Int J Syst Bacteriol. 1970;20:241-8.

9. Mykytczuk NC, Wilhelm RC, Whyte LG. Planococcus halocryophilus sp. nov., an extreme sub-zero species from high Arctic permafrost. Int J Syst Evol Microbiol. 2012;62:1937-44.

10. Lay CY, Mykytczuk NC, Niederberger TD, Martineau C, Greer CW, Whyte LG. Microbial diversity and activity in hypersaline high Arctic spring channels. Extremophiles. 2012;16:177-91.

11. Mykytczuk NC, Foote SJ, Omelon CR, Southam G, Greer CW, Whyte LG. Bacterial growth at -15 degrees $C$; molecular insights from the permafrost bacterium Planococcus halocryophilus Or1. ISME J. 2013;7:1211-26.

12. Hupert-Kocurek K, Guzik U, Wojcieszynska D. Characterization of catechol 2,3-dioxygenase from Planococcus sp. strain S5 induced by high phenol concentration. Acta Biochim Pol. 2012;59:345-51.

13. Li H, Liu YH, Luo N, Zhang XY, Luan TG, Hu JM, Wang ZY, Wu PC, Chen MJ, Lu JQ. Biodegradation of benzene and its derivatives by a psychrotolerant and moderately haloalkaliphilic Planococcus sp. strain ZD22. Res Microbiol. 2006;157:629-36.

14. Tamura K, Peterson D, Peterson N, Stecher G, Nei M, Kumar S. MEGA5: molecular evolutionary genetics analysis using maximum likelihood, evolutionary distance, and maximum parsimony methods. Mol Biol Evol. 2011;28:2731-9. 
15. Reddy GS, Prakash JS, Vairamani M, Prabhakar S, Matsumoto Gl, Shivaji S Planococcus antarcticus and Planococcus psychrophilus spp. nov. isolated from cyanobacterial mat samples collected from ponds in Antarctica. Extremophiles. 2002;6:253-61.

16. Pagani I, Liolios K, Jansson J, Chen IM, Smirnova T, Nosrat B, Markowitz VM, Kyrpides NC. The genomes OnLine database (GOLD) v.4: status of genomic and metagenomic projects and their associated metadata. Nucleic Acids Res. 2012:40:D571-9.

17. Aziz RK, Bartels D, Best AA, DeJongh M, Disz T, Edwards RA, Formsma K, Gerdes S, Glass EM, Kubal M, et al. The RAST server: rapid annotations using subsystems technology. BMC Genomics. 2008;9:75.

18. Zdobnov EM, Apweiler R. InterProScan--an integration platform for the signature-recognition methods in InterPro. Bioinformatics. 2001;17:847-8.

19. Mistry J, Finn R. Pfam: a domain-centric method for analyzing proteins and proteomes. Methods Mol Biol. 2007;396:43-58.

20. Lowe TM, Eddy SR. tRNAscan-SE: a program for improved detection of transfer RNA genes in genomic sequence. Nucleic Acids Res. 1997;25:955-64.

21. Finn RD, Clements J, Eddy SR. HMMER web server: interactive sequence similarity searching. Nucleic Acids Res. 2011;39:W29-37.

22. Zhou Y, Liang Y, Lynch KH, Dennis JJ, Wishart DS. PHAST: a fast phage search tool. Nucleic Acids Res. 2011;39:W347-52.

23. Hsiao W, Wan I, Jones SJ, Brinkman FS. IslandPath: aiding detection of genomic islands in prokaryotes. Bioinformatics. 2003;19:418-20.

24. Krogh A, Larsson B, von Heijne G, Sonnhammer EL. Predicting transmembrane protein topology with a hidden Markov model: application to complete genomes. J Mol Biol. 2001;305:567-80

25. Petersen TN, Brunak S, von Heijne G, Nielsen H. SignalP 4.0: discriminating signal peptides from transmembrane regions. Nat Methods. 2011;8:785-6.

26. Goris J, Konstantinidis KT, Klappenbach JA, Coenye T, Vandamme P, Tiedje JM. DNA-DNA hybridization values and their relationship to whole-genome sequence similarities. Int J Syst Evol Microbiol. 2007;57:81-91.

27. Juhas M, van der Meer JR, Gaillard M, Harding RM, Hood DW, Crook DW. Genomic islands: tools of bacterial horizontal gene transfer and evolution. FEMS Microbiol Rev. 2009;33:376-93.

28. Janssen BD, Garza-Sanchez F, Hayes CS. YoeB toxin is activated during thermal stress. Microbiology. 2015;4:682-97.

29. Arnaouteli S, Giastas P, Andreou A, Tzanodaskalaki M, Aldridge C, Tzartos SJ, Vollmer W, Eliopoulos E, Bouriotis V. Two putative polysaccharide deacetylases are required for osmotic stability and cell shape maintenance in Bacillus anthracis. J Biol Chem. 2015;290:13465-78.

30. Lipscomb JD. Mechanism of extradiol aromatic ring-cleaving dioxygenases. Curr Opin Struct Biol. 2008;18:644-9.

31. Hayes RP, Green AR, Nissen MS, Lewis KM, Xun L, Kang C. Structural characterization of 2,6-dichloro-p-hydroquinone 1,2-dioxygenase (PcpA) from Sphingobium chlorophenolicum, a new type of aromatic ring-cleavage enzyme. Mol Microbiol. 2013;88:523-36.

32. Conaway CC, Nie G, Hussain NS, Fiala ES. Comparison of oxidative damage to rat liver DNA and RNA by primary nitroalkanes, secondary nitroalkanes, cyclopentanone oxime, and related compounds. Cancer Res. 1991;51:3143-7.

33. Ha JY, Min JY, Lee SK, Kim HS, Kim DJ, Kim KH, Lee HH, Kim HK, Yoon HJ, Suh SW. Crystal structure of 2-nitropropane dioxygenase complexed with FMN and substrate. Identification of the catalytic base. J Biol Chem. 2006; 281:18660-7.

34. Caballero A, Lazaro JJ, Ramos JL, Esteve-Nunez A. PnrA, a new nitroreductase-family enzyme in the TNT-degrading strain Pseudomonas putida JLR11. Environ Microbiol. 2005;7:1211-9.

35. Anantharaman V, lyer LM, Aravind L. Ter-dependent stress response systems: novel pathways related to metal sensing, production of a nucleoside-like metabolite, and DNA-processing. Mol BioSyst. 2012;8:3142-65.

36. Kim J, Park W. Oxidative stress response in Pseudomonas putida. Appl Microbiol Biotechnol. 2014;98:6933-46.

37. Park W, Jeon CO, Cadillo H, DeRito C, Madsen EL. Survival of naphthalenedegrading Pseudomonas putida NCIB 9816-4 in naphthalene-amended soils: toxicity of naphthalene and its metabolites. Appl Microbiol Biotechnol. 2004;64:429-35.

38. Loi W, Rossius M, Antelmann $\mathrm{H}$. Redox regulation by reversible protein Sthiolation in bacteria. Front Microbiol. 2015;6:187.

39. Sharma SV, Arbach M, Roberts AA, Macdonald CJ, Groom M, Hamilton CJ. Biophysical features of bacillithiol, the glutathione surrogate of Bacillus subtilis and other firmicutes. Chembiochem. 2013;14:2160-8.
40. Chintalapati S, Kiran MD, Shivaji S. Role of membrane lipid fatty acids in cold adaptation. Cell Mol Biol. 2004:50:631-42.

41. Irazusta V, Nieto-Penalver CG, Cabral ME, Amoroso MJ, de Figueroa LIC. Relationship among carotenoid production, copper bioremediation and oxidative stress in Rhodotorula mucilaginosa RCL-11. Process Biochem. 2013; 48:803-9.

42. Field D, Garrity G, Gray T, Morrison N, Selengut J, Sterk P, Tatusova T, Thomson N, Allen MJ, Angiuoli SV, et al. The minimum information about a genome sequence (MIGS) specification. Nat Biotechnol. 2008;26:541-7.

43. Woese CR, Kandler O, Wheelis ML. Towards a natural system of organisms: proposal for the domains archaea, Bacteria, and Eucarya. Proc Natl Acad Sci U S A. 1990;87:4576-9.

44. Gibbons NE, Murray RGE. Proposals concerning the higher taxa of Bacteria. Int J Syst Evol Microbiol. 1978;28:1-6.

45. Euzeby J. Validation list no. 132. List of new names and new combinations previously effectively, but not validly, published. Int I Syst Evol Microbiol. 2010;60:469-72

46. Skerman VBD, McGowan V, Sneath PHA. Approved lists of bacterial names. Int J Syst Evol Microbiol. 1980;30:225-420.

47. Ashburner M, Ball CA, Blake JA, Botstein D, Butler H, Cherry JM, Davis AP, Dolinski K, Dwight SS, Eppig JT, et al. Gene ontology: tool for the unification of biology. The Gene Ontology Consortium. Nat Genet. 2000;25:25-9.

\section{Ready to submit your research? Choose BMC and benefit from:}

- fast, convenient online submission

- thorough peer review by experienced researchers in your field

- rapid publication on acceptance

- support for research data, including large and complex data types

- gold Open Access which fosters wider collaboration and increased citations

- maximum visibility for your research: over $100 \mathrm{M}$ website views per year

At BMC, research is always in progress.

Learn more biomedcentral.com/submissions 